Article

\title{
Improvements of a COMS Land Surface Temperature Retrieval Algorithm Based on the Temperature Lapse Rate and Water Vapor/Aerosol Effect
}

\section{A-Ra Cho ${ }^{1}$, Youn-Young Choi ${ }^{2}$ and Myoung-Seok Suh ${ }^{2, *}$}

1 Department of Climate and Air Quality Research, National Institute of Environmental Research, Hwangyeong-ro, Kyungseo-dong, Incheon 404-708, Korea; E-Mail: ara87@korea.kr

2 Department of Atmospheric Science, Kongju National University, 56, Gongjudaehak-ro, Gongju-si, Chungcheongnam-do 314-701, Korea; E-Mail: choiyoyo@kongju.ac.kr

* Author to whom correspondence should be addressed; E-Mail: sms416@kongju.ac.kr; Tel.: +82-41-850-8533; Fax: +82-41-850-8527.

Academic Editors: Markus Neteler and Prasad S. Thenkabail

Received: 7 November 2014 / Accepted: 2 February 2015 / Published: 5 February 2015

\begin{abstract}
The National Meteorological Satellite Center in Korea retrieves land surface temperature (LST) by applying the split-window LST algorithm (CSW_v1.0) to Communication, Ocean, and Meteorological Satellite (COMS) data. Considerable errors were detected under conditions of high water vapor content or temperature lapse rates during validation with Moderate Resolution Imaging Spectroradiometer (MODIS) LST because of the too simplified LST algorithm. In this study, six types of LST retrieval equations (CSW_v2.0) were developed to upgrade the CSW_v1.0. These methods were developed by classifying "dry," "normal," and "wet" cases for day and night and considering the relative sizes of brightness temperature difference (BTD) values. Similar to CSW_v1.0, the LST retrieved by CSW_v2.0 had a correlation coefficient of 0.99 with the prescribed LST and a slightly larger bias of $-0.03 \mathrm{~K}$ from $0.00 \mathrm{~K}$; the root mean square error (RMSE) improved from $1.41 \mathrm{~K}$ to $1.39 \mathrm{~K}$. In general, CSW_v2.0 improved the retrieval accuracy compared to CSW_v1.0, especially when the lapse rate was high (mid-day and dawn) and the water vapor content was high. The spatial distributions of LST retrieved by CSW_v2.0 were found to be similar to the MODIS LST independently of the season, day/night, and geographic locations. The validation using one year's MODIS LST data showed that CSW_v2.0 improved the retrieval accuracy of LST in terms of correlations (from 0.988 to 0.989), bias (from $-1.009 \mathrm{~K}$ to $0.292 \mathrm{~K}$ ), and RMSEs (from $2.613 \mathrm{~K}$ to $2.237 \mathrm{~K}$ ).
\end{abstract}


Keywords: land surface temperature; split-window algorithm; COMS; MODIS

\section{Introduction}

Land surface temperature (LST) is an important factor that controls the sensible heat flux and latent heat flux [1-3], and it has been used as a biophysical indicator of the land surface in many studies where estimates of the radiation balance, temperature, and evapotranspiration rates were determined. Moreover, LST is used often in studies of urban heat islands [4-9]. In all of these studies, LSTs observed at high temporal and spatial resolutions are required to ensure the usability of the data [10-13]. However, since the land surfaces are composed of various elements and specific heat is small, LST, which is more prone to temporal/spatial variations than other meteorological elements, is not sufficiently accurate compared to other field observation data $[13,14]$.

Recently, with the remarkable advancements in remote sensing technologies, satellite data with relatively high temporal/spatial resolutions and accuracy are becoming more readily available for various research applications, such as the surface energy balance, data assimilations of various numerical models, and climate change. Accordingly, many algorithms have been developed to retrieve LST from various satellite products $[11,12,15-20]$. Over time, the performances of LST algorithms have greatly improved because of advances in the spatial resolving power of geostationary weather satellites and increases in the radiation resolving power and observation cycles [3,21-26]. Considering the large spatial/temporal variations of LST, recent attempts at and on-site applications of LST retrieval from geostationary meteorological satellite data have been very promising [27-31].

Cho and Suh (2013) developed an algorithm (CSW_v1.0) that retrieves LST from satellite data collected with the Communication, Ocean, and Meteorological Satellite (COMS), South Korea's first geostationary satellite [25]. An evaluation of the retrieval accuracy of LST retrieved by CSW_v1.0 with Moderate Resolution Imaging Spectroradiometer (MODIS) LST yielded satisfactory results, with an annual average bias of $-1.009 \mathrm{~K}$, a root mean square error (RMSE) of $2.613 \mathrm{~K}$, and a correlation coefficient of 0.988 . However, in cases where there was a high lapse rate (i.e., a large difference between the LST and air temperature), which happens mostly during dawn and at mid-day, and in cases where there was a large brightness temperature difference (BTD), which happens mostly when water vapor or aerosol concentrations are high, the retrieval accuracy was found to decrease noticeably. This may be explained by the fact that the algorithms that retrieve the LST from the satellite data are very sensitive to water vapor amounts and lapse rates, as noted by Kerr et al. [32]. This is mainly caused by the different and non-linear absorption properties of water vapor and aerosols between two infrared channels, although the two infrared channels of COMS are located at the window region. Therefore, to improve the accuracy of retrieved LST, accurate understanding and consideration of the water vapor distribution as well as the lapse rate are required in the LST retrieval process $[12,33,34]$. However, realistically, this is not easy to consider because water vapor and aerosols (these have large but different influences on the wavelength band of $8-13 \mu \mathrm{m}$, which is an atmospheric window region) have large short-term variations and uneven distributions. According to Goïta and Royer [35], an uncertainty for water vapor of $\pm 0.5 \mathrm{~g} \cdot \mathrm{cm}^{-2}$ can lead to a LST error of $2.5 \mathrm{~K}$. Wan and Dozier suggested that the water vapor amount, 
LST, and lapse rate should be considered quantitatively when calculating LST with the split-window method under conditions where the column water vapor amount is large and the satellite zenith angle (SZA) exceeds $45^{\circ}$ [12].

As a method for lowering the sensitivity to water vapor content, Sun and Pinker [3] proposed a non-linear split-window algorithm, and Sobrino and Raissouni [36] and Sobrino et al. [37] developed split-window algorithms that parameterize the effects of water vapor. In the case of the lapse rate, Sobrino and Romaguera [26] and the MODIS Land Surface Group separated algorithms into day and night by taking into account the time-dependent variation between LST and surface emissivity. In brief, the retrieval accuracy can be improved by developing multiple retrieval equations taking into consideration the non-linear characteristics of factors such as water vapor/aerosols and lapse rate, which affect the accuracy of the retrieved LST [38].

In this study, to minimize the drawbacks of CSW_v1.0, which was developed by Cho and Suh [25], we developed an improved algorithm (CSW_v2.0) that considers the lapse rate and water vapor/aerosol effects, which are different between day and night and in space and time. We think that separation of LST retrieval equations according to the lapse rate and atmospheric conditions can improve the retrieval accuracy because the effects of water vapor/aerosols and lapse rate are non-linear according to their amount/magnitude. To evaluate the retrieval accuracy of this upgraded algorithm, we analyzed the improvement effects according to the factors that have impacts on LST retrieval and conducted comparative evaluations with MODIS LST data.

\section{Data and Methods}

\subsection{Data}

In this study, we used IR1 $(10.8 \mu \mathrm{m})$, IR2 $(12 \mu \mathrm{m})$, and cloud mask data that were sensed by COMS. These data were provided by the National Meteorological Satellite Center (NMSC) of the Korea Meteorological Administrator (KMA) [39]; COMS is South Korea's first geostationary multi-purpose satellite, and it is located at an altitude of $36,000 \mathrm{~km}$ above Earth's equator and at a longitude of $128.2^{\circ}$. The observation interval for COMS data is $15 \mathrm{~min}$ and the spatial resolution is about $4 \mathrm{~km}$. We used one year's satellite data from April 2011 to March 2012. Since the LST can be retrieved from the satellite by using the split-window method only when the sky is clear, the retrieval was performed only for pixels of clear sky in the cloud mask dataset from COMS.

The majority of LST retrieval algorithms for the split-window method assume that the surface emissivity of each channel is already known. In this study, the surface emissivity data produced with the vegetation cover method (VCM) proposed by Valor and Caselles [40] were used, as in the study by Cho and Suh [25]. Furthermore, for the atmospheric vertical profile required in the radiative transfer simulation process, we used the TIGR (Thermodynamic Initial Guess Retrieval) data from 359 positions where the SZA did not exceed $50^{\circ}$ from COMS, which was obtained from among the whole TIGR2000_6CORPS dataset [41]. The locations of 359 TIGR data sets are shown in Figure 1 along with the location of COMS. 


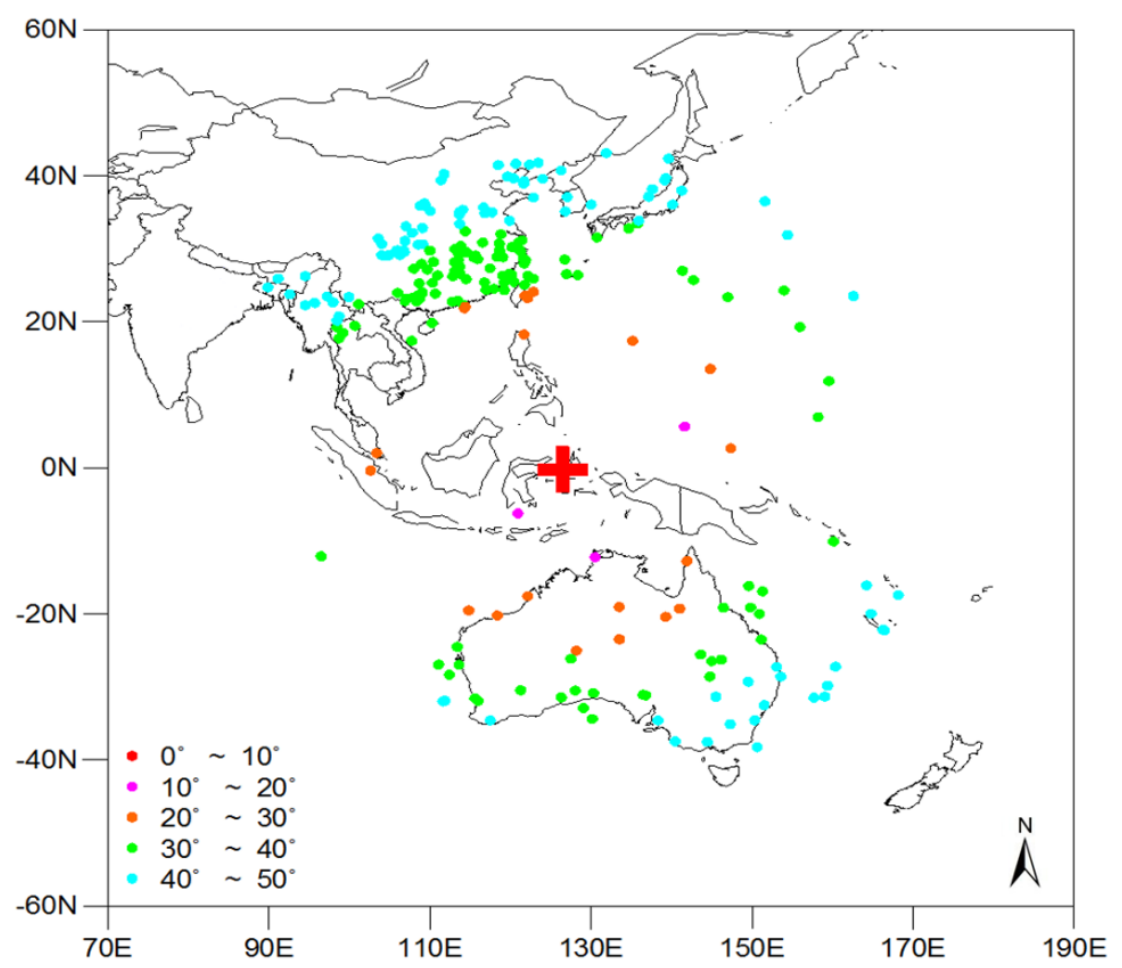

Figure 1. Spatial distribution of Thermodynamic Initial Guess Retrieval (TIGR) data used in this study. The nadir position of COMS is represented by “+”.

In addition to the limited number of ground observations, the ground-observed LSTs have limitations with regards to their ability to serve as validating data for the CSW_v2.0 developed in this study because they cannot represent the area-averaged LSTs for the resolution of satellite data, which have large spatial variations [13]. As an alternative, this study performed a comparative evaluation with the MODIS LST Version 5 product (MOD11_L2, MYD11_L2; Version 5), which is known for its relatively high retrieval accuracy with a bias of $1 \mathrm{~K}$ and RMSE of $0.7 \mathrm{~K}$ [42]; the same methods used in the studies carried out by Cho and Suh [25] and Frey et al. [43] are applied here.

\subsection{Methods}

The existing CSW_v1.0 developed by Cho and Suh [25] expressed the contributions of BTD, surface emissivity, and SZA for various atmospheric conditions in a single equation through the simulation of Moderate Resolution Atmospheric Transmission Version 4 (MODTRAN4) [44], which is a radiative transfer model (RTM). Cho and Suh [25] have provided the development process and retrieval performance of the CSW_v1.0 in detail. The CSW_v1.0 is as follows:

$$
\begin{gathered}
\left(\mathrm{LST}=29.7890+0.8866 \mathrm{~T}_{\mathrm{IR} 1}+2.1443 \Delta \mathrm{T}+0.1298 \Delta \mathrm{T}^{2}+0.7911(\sec \theta-1)+\right. \\
56.6851(1-\bar{\varepsilon})-122.172 \Delta \varepsilon) .
\end{gathered}
$$

In Equation (1), TIR1 is the brightness temperature of IR1, $\Delta T$ is the BTD of the IR1 and IR2 channels, $\theta$ is the SZA of COMS, $\bar{\varepsilon}$ is the average surface emissivity of the IR1 and IR 2 channels, and $\Delta \varepsilon$ is the surface emissivity difference (IR1 - IR2). Compared to MODIS LST, the LST retrieved by CSW_v1.0 has a bias of $-1.009 \mathrm{~K}, \mathrm{RMSE}$ of $2.613 \mathrm{~K}$, and a correlation coefficient of 0.988 . However, its retrieval accuracy was found to decrease when the lapse rate $\left(T_{s}-T_{a}\right)$ and BTD were large. 
Figure 2 is a flow chart that shows the research processes of this study. The major differences from the CSW_v1.0 development process are as follows: (1) the RTM simulations were performed during the day and night according to lapse rate and (2) separate algorithms were developed for wet/normal/dry states according to the size of the BTD to reflect the effects of water vapor and aerosols more specifically. In the first stage, the lapse rate conditions prescribed by the RTM simulation were divided into day and night conditions to take the lapse rate into consideration in the development process of CSW_v2.0. In CSW_v1.0, LST values were prescribed at $2 \mathrm{~K}$ intervals from $\left(T_{a}-6\right) \mathrm{K}$ to $\left(T_{a}+16\right) \mathrm{K}$ to make one pseudo match-up dataset; in CSW_v2.0, in contrast, we made two pseudo match-up datasets by prescribing from $\left(T_{a}-2\right) \mathrm{K}$ to $\left(T_{a}+16\right) \mathrm{K}$ for the day, and from $\left(T_{a}-6\right) \mathrm{K}$ to $\left(T_{a}+2\right) \mathrm{K}$ for the night. The interval for the lapse rate condition was set to $2 \mathrm{~K}$ like that of CSW_v1.0. For the RTM, MODTRAN4 [44] was used, as in CSW_v1.0.

In the second stage, to consider the effects of water vapor and aerosols, the two pseudo match-up datasets simulated earlier were classified into dry and wet conditions according to the critical value of BTD. The critical value was determined on the basis of the error analysis results for CSW_v1.0 [25] (Cho and Suh, 2013), and in general, those that show large errors when the BTD has a negative value or is greater than or equal to $4 \mathrm{~K}$ were selected as boundary values. The "dry" algorithm was assigned to BTD less than or equal to $0 \mathrm{~K}$ since the water vapor content was low and aerosols were dominant in general; the "wet" algorithm was assigned to values greater than $4 \mathrm{~K}$ since water vapor was dominant; and the "normal" algorithm was assigned to values between $0 \mathrm{~K}$ and $4 \mathrm{~K}$ (Table 1). In this process, the single regression equation of CSW_v1.0 was divided into six specific retrieval equations (2 (day, night) $\times 3$ (dry, normal, wet)) according to the lapse rate, water vapor content, and aerosol conditions (Equations (2)-(7)). As shown in Equations (2)-(7), the effects of water vapor and aerosols according to the atmospheric conditions are reflected in the coefficients of BTD and BTD 2 .

Table 1. Summary of LST retrieval equations according to the BTD ranges. The number indicates the equation number in the text.

\begin{tabular}{ccc}
\hline Conditions & BTD Ranges & LST Equation \\
\hline Dry & BTD $<0$ & (2) for Day, (5) for Night \\
\hline Dry-Normal & $-1 \leq$ BTD $\leq 1$ & $\begin{array}{c}\text { Day: weighted sum of (2) and (3) } \\
\text { Night: weighted sum of (5) and (6) }\end{array}$ \\
\hline Normal & $0<$ BTD $<4$ & (3) for Day, (6) for Night \\
\hline Normal-Wet & $3 \leq$ BTD $\leq 5$ & $\begin{array}{c}\text { Day: weighted sum of (3) and (4) } \\
\text { Night: weighted sum of (6) and (7) }\end{array}$ \\
\hline Wet & BTD $>4$ & (4) for Day, (7) for Night \\
\hline
\end{tabular}

The meanings for each variable are the same as those for Equation (1). The developed algorithms can be applied easily to day and night, but temporal discontinuities can occur during twilight and dawn because of differences between the algorithms. To resolve this problem, when the Solar Zenith Angle (SoZA) for each pixel is between $80^{\circ}$ and $100^{\circ}$, it was assumed to be twilight and dawn. Considering the SoZA in the developed day and night algorithms, the weight ( $\omega$ ) of Equation (9) was given linearly to resolve the discontinuity between the algorithms. 


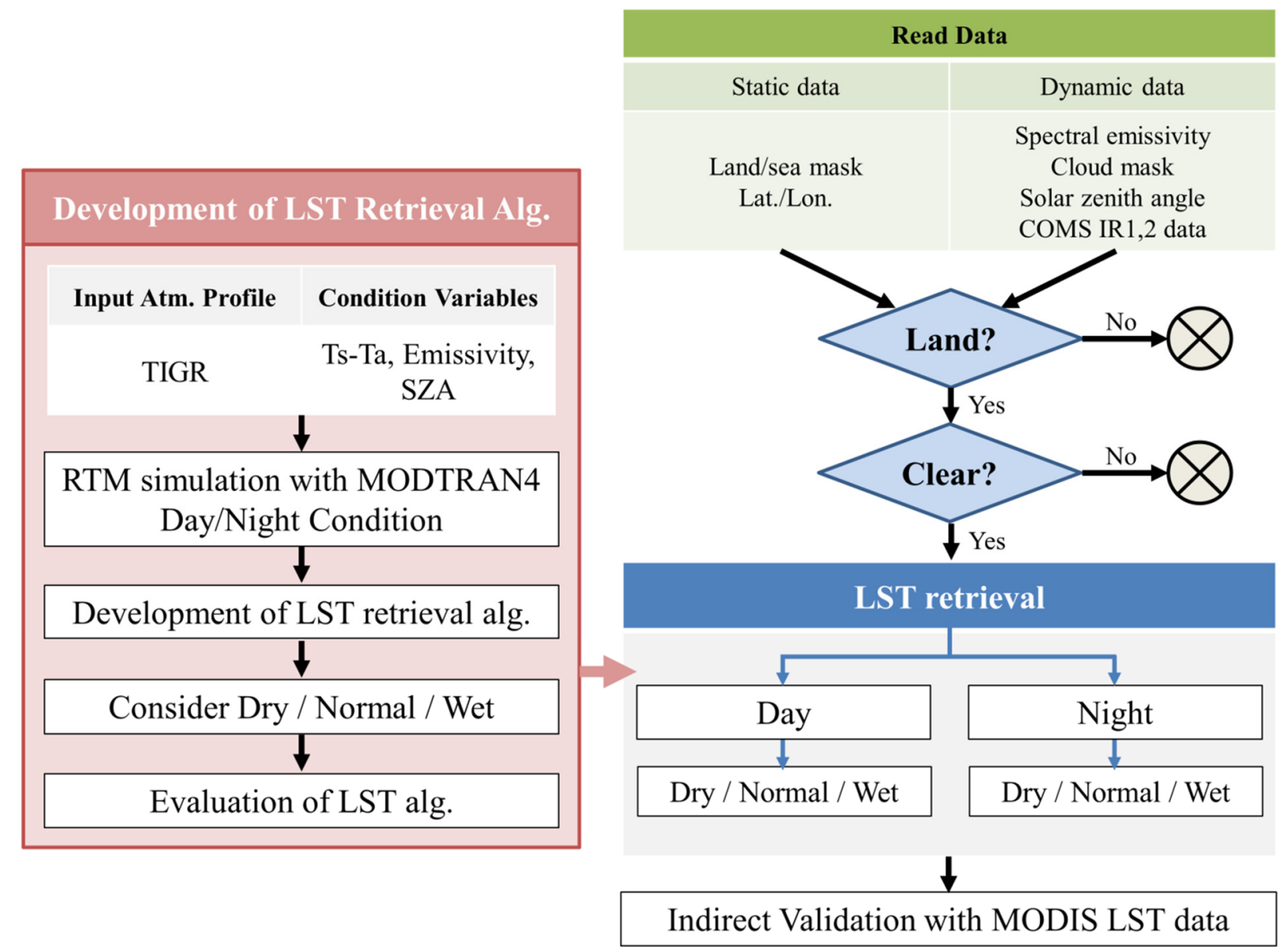

Figure 2. Flow chart for the development and retrieval process of land surface temperature from COMS data.

$$
\begin{gathered}
\left(L S T_{\text {day } / \text { dry }}=25.2630+0.9094 T_{I R 1}+3.6544 B T D+0.4427 B T D^{2}-\right. \\
2.7314(\sec \theta-1)+44.9390(1-\bar{\varepsilon})-153.993 \Delta \varepsilon) \\
\left(L S T_{\text {day } / \text { nor. }}=11.7969+0.9548 T_{I R 1}+1.3027 B T D+0.2092 B T D^{2}+\right. \\
0.2506(\sec \theta-1)+56.4788(1-\bar{\varepsilon})-110.799 \Delta \varepsilon) \\
\left(L S T_{\text {day } / \text { wet }}=79.1358+0.6801 T_{I R 1}+6.2170 B T D-0.2131 B T D^{2}+\right. \\
1.6207(\sec \theta-1)+61.7844(1-\bar{\varepsilon})-127.603 \Delta \varepsilon) \\
\left(L S T_{\text {nig./dry }}=32.0297+0.8834 T_{I R 1}+1.6431 B T D-0.7119 B T D^{2}-\right. \\
3.1955(\sec \theta-1)+39.8000(1-\bar{\varepsilon})-144.0990 \Delta \varepsilon) \\
\left(L S T_{\text {nig./nor. }}=10.4334+0.9590 T_{I R 1}+1.3623 B T D+0.1935 B T D^{2}+\right. \\
0.2044(\sec \theta-1)+51.3197(1-\bar{\varepsilon})-86.8015 \Delta \varepsilon) \\
\left(L S T_{\text {nig./wet }}=29.2220+0.8323 T_{I R 1}+10.6588 B T D-0.8091 B T D^{2}+\right. \\
0.8938(\sec \theta-1)+53.6692(1-\bar{\varepsilon})-88.480 \Delta \varepsilon) \\
\left(L S T=\omega \times L S T_{d a y}+(1-\omega) \times L S T_{\text {nig. }}\right)
\end{gathered}
$$




$$
\begin{aligned}
& \left(\omega=-\frac{1}{20} \times(\text { SoZA })+5\left(80^{\circ} \leq \text { SoZA } \leq 100^{\circ}\right),\right. \\
& \left.\omega=1.0\left(\text { SoZA } \leq 80^{\circ}\right) \omega=0.0\left(\text { SoZA } \geq 100^{\circ}\right)\right)
\end{aligned}
$$

In Equations (8) and (9), $\omega$ represents the weight, and $L S T_{\text {day }}$ and $L S T_{\text {nig }}$ are the LST values retrieved by applying the day and night algorithms, respectively. When the SoZA was less than or equal to $80^{\circ}$, the day algorithm was applied, and when it was greater than or equal to $100^{\circ}$, the night algorithm was applied. Furthermore, as shown in Table 1 , reflecting $\pm 1 \mathrm{~K}$ in the critical value of BTD for the developed algorithms between dry and normal, and between normal and wet, the discontinuities between the algorithms were resolved by linearly assigning the weights $(\omega)$ of Equations (11) and (13).

$$
\begin{gathered}
\left(\mathrm{LST}=\omega \times L S T_{d r y}+(1-\omega) \times L S T_{\text {normal }}\right) \\
\left(\omega=-\frac{1}{2} \times(\mathrm{BTD}-0 \mathrm{~K})+\frac{1}{2}(-1 \mathrm{~K} \leq \mathrm{BTD} \leq+1 \mathrm{~K}),\right. \\
\omega=1.0(\mathrm{BTD} \leq-1 \mathrm{~K}) \omega=0.0(\mathrm{BTD} \geq+1 \mathrm{~K})) \\
\left(\mathrm{LST}=\omega \times L S T_{\text {normal }}+(1-\omega) \times L S T_{\text {wet }}\right) \\
\left(\omega=-\frac{1}{2} \times(\mathrm{BTD}-4 \mathrm{~K})+\frac{1}{2}(3 \mathrm{~K} \leq \mathrm{BTD} \leq 5 \mathrm{~K}),\right. \\
\omega=1.0(\mathrm{BTD} \leq 3 \mathrm{~K}) \omega=0.0(\mathrm{BTD} \geq 5 \mathrm{~K}))
\end{gathered}
$$

In Equations (10)-(13), the BTD represents the brightness temperature difference, $\omega$ is the weight, and $\mathrm{LST}_{\mathrm{dry}}, \mathrm{LST}_{\text {normal }}$, and $\mathrm{LST}_{\text {wet }}$ are the LST values retrieved by the dry/normal/wet algorithms, respectively. By applying the linear weights for the discontinuities between six specific retrieval equations, we could derive improved LST retrieval algorithms that minimize the time-dependent discontinuities among the algorithms (CSW_v2.0).

\section{Results}

\subsection{Evaluation of the CSW_v2.0 Algorithm}

To evaluate the improvement effects of CSW_v2.0, a comparison was made with the retrieval accuracy of CSW_v1.0. For this, the LST that was prescribed in the simulation process of RTM (prescribed LST) and the LST that was retrieved by the algorithm (estimated LST) were compared. To estimate the LST, the brightness temperature of IR channels 1 and 2 simulated with the RTM, the prescribed surface emissivity, and the SZA data of atmospheric vertical data points were substituted into the retrieval equation. Because the SoZA that is required to decide between the day and night modes cannot be calculated from the data retrieved by radiative transfer simulations, they were substituted with the differences $(\Delta \mathrm{T})$ between the temperature and LSTs provided in the simulation and corresponding atmospheric temperatures. LSTs less than or equal to $\left(\mathrm{T}_{\mathrm{a}}-2\right) \mathrm{K}$ were assigned to the night mode algorithm and those greater than or equal to $\left(T_{a}+2\right) K$ to the day mode algorithm, with the values in between assumed to be twilight and dawn. The LST was estimated by substituting the weight $(\omega)$ of Equation (15) that meets the $\Delta \mathrm{T}$ condition of Equation (14).

Figure 3 shows (a) scatter plots and (b) bias distributions between the estimated and prescribed LSTs; the graphs demonstrate that both algorithms retrieve LST properly. CSW_v2.0 has considerably reduced the problem where CSW_v1.0 underestimated in the 300-320 K range. However, the problem of overestimation in the range $270-290 \mathrm{~K}$ was not resolved satisfactorily. CSW_v2.0 not only maintained 
the high retrieval accuracy with a 0.99 correlation between the prescribed LST and $-0.03 \mathrm{~K}$ bias, but also reduced the RMSE from $1.41 \mathrm{~K}$ to $1.39 \mathrm{~K}$. Although bias for the two algorithms displayed a dense normal distribution at $0 \mathrm{~K}$, the standard deviation of the CSW_v2.0 bias was $1.19 \mathrm{~K}$ compared to 1.35 $\mathrm{K}$ for the CSW_v1.0 bias, which demonstrates that the error was decreased.

$$
\begin{gathered}
\left(\mathrm{LST}=\omega \times L S T_{\text {day }}+(1-\omega) \times L S T_{\text {nig. }}\right) \\
\left(\omega=\frac{1}{4} \times \Delta \mathrm{T}+\frac{1}{2}(-2 K<\Delta \mathrm{T}<2 K),\right. \\
\omega=1.0(\Delta \mathrm{T} \geq 2 \mathrm{~K}) \\
\omega=0.0(\Delta \mathrm{T} \leq-2 \mathrm{~K}))
\end{gathered}
$$

(a) Scatter plots
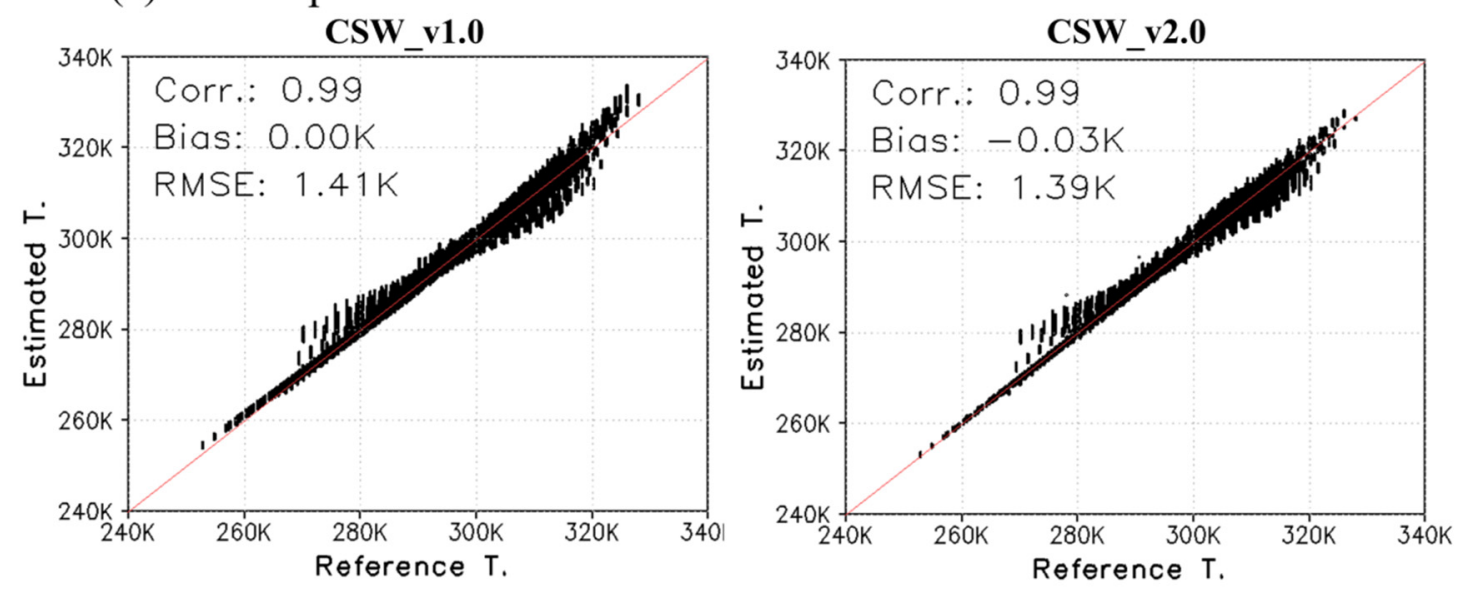

(b) Bias distributions
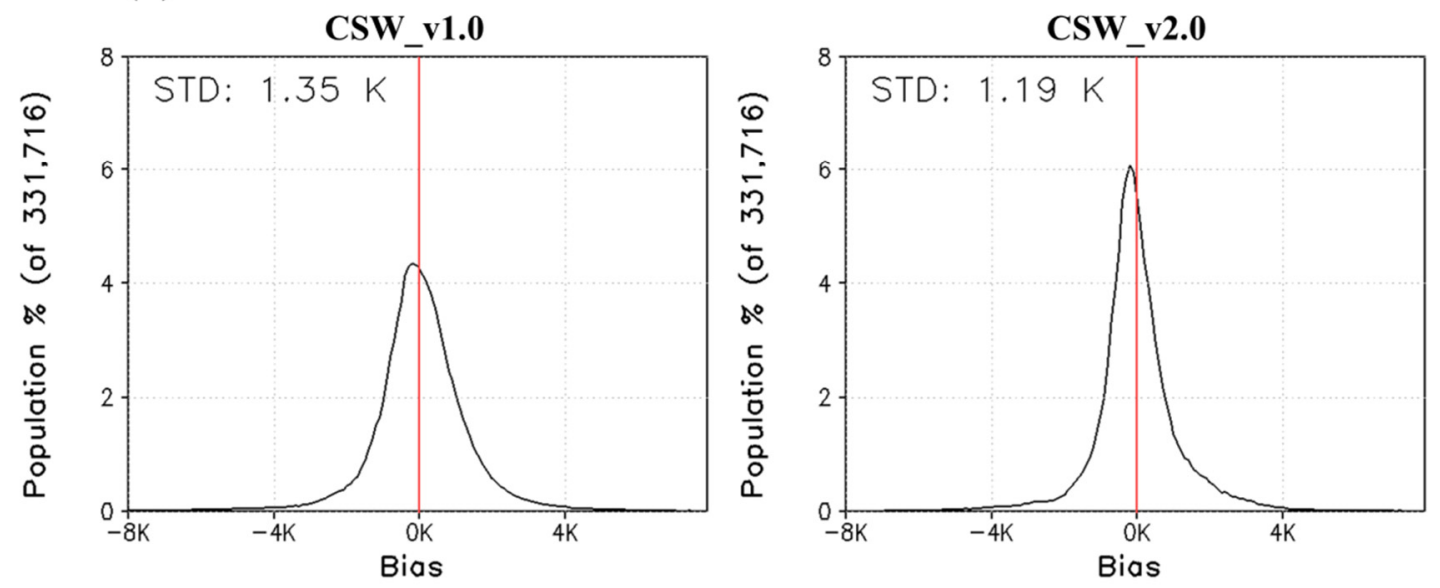

Figure 3. (a) Scatter plot and (b) histogram of the difference between the prescribed LST and the estimated LST using COMS split-window LST retrieval algorithms, Version 1 (left) and Version 2 (right), for the full range of simulation conditions given in Table 2.

Table 2 outlines the number of data points for each condition of the major factors evaluated with the entire pseudo match-up dataset that was composed through the simulations of RTM (MODTRAN4). In the cases for the lapse rates and surface emissivity differences, an adequate number of simulations were conducted according to the experimental design conditions. However, in the case of the BTD, the number of simulated data varied depending on the BTD values because of the characteristics of the TIGR data used in the simulation process; particularly, since cases with large amounts of aerosols or extremely high 
humidity levels (e.g., $-2 \mathrm{~K}$ and $6 \mathrm{~K}$ ) rarely happen, the number of simulated data was small compared to other conditions. Furthermore, the number of simulated data points varied between the SZAs because there were not many TIGR points over the islands in Southeast Asia [25] (Cho and Suh, 2013).

Table 2. The number of pseudo match-up data points according to the simulation conditions.

\begin{tabular}{ccccccccccccc}
\hline $\mathbf{T}_{\boldsymbol{s}}-\boldsymbol{T}_{\boldsymbol{a}}(\boldsymbol{K})$ & $\mathbf{- 6}$ & $-\mathbf{4}$ & $-\mathbf{2}$ & $\mathbf{0}$ & $\mathbf{2}$ & $\mathbf{4}$ & $\mathbf{6}$ & $\mathbf{8}$ & $\mathbf{1 0}$ & $\mathbf{1 2}$ & $\mathbf{1 4}$ & $\mathbf{1 6}$ \\
\hline Cases & 27,643 & 27,643 & 27,643 & 27,643 & 27,643 & 27,643 & 27,643 & 27,643 & 27,643 & 27,643 & 27,643 & 27,643 \\
BTD $(\boldsymbol{K})$ & -3 & -2 & -1 & 0 & 1 & 2 & 3 & 4 & 5 & 6 & 7 & \\
Cases & 142 & 1529 & 18,297 & 51,455 & 66,442 & 67,815 & 58,758 & 40,462 & 20,951 & 5429 & 435 & \\
SZA $\left({ }^{\circ}\right)$ & $\sim 10$ & $10 \sim 15$ & $15 \sim 20$ & $20 \sim 25$ & $25 \sim 30$ & $30 \sim 35$ & $35 \sim 40$ & $40 \sim 45$ & $45 \sim 50$ & & & \\
Cases & 924 & 3696 & 12,012 & 21,252 & 48,048 & 92,400 & 78,540 & 67,452 & 7392 & & & \\
$\Delta$ Emis. & -0.012 & -0.008 & -0.004 & 0 & 0.004 & 0.008 & 0.012 & & & & & \\
Cases & 47,388 & 47,388 & 47,388 & 47,388 & 47,388 & 47,388 & 47,388 & & & & & \\
\hline
\end{tabular}

Figures 4 and 5 compare the correlation, bias, and RMSE between the prescribed LST and estimated LST, respectively, according to the lapse rate and BTD before and after the algorithm was upgraded. The bar graphs show the statistics for both versions and the line graphs show the improvement rate. As shown in Figure 4, the retrieval accuracy of CSW_v2.0 was higher than that of CSW_v1.0 regardless of the lapse rate condition. Particularly, the improvement in retrieval performance was high when the difference between temperature and LST was large, presumably because of the development of separate LST retrieval algorithms for the lapse rate. However, the improvement rate was rather low when the difference between temperature and LST was less than $\pm 2 \mathrm{~K}$; this may have occurred because we calculated the weighted average of the retrieved temperatures for the day/night algorithms without developing a separate algorithm for this section. Furthermore, the bias and RMSE were greatly improved under the condition of large BTD values as a result of the development of three LST retrieval algorithms according to the concentrations of water vapor and aerosol in the atmosphere.

Figure 6 shows the RMSEs between the estimated LST and prescribed LST for CSW_v1.0 (left) and v2.0 (center), as well as their differences (right) according to the variables (lapse rates, BTDs, surface emissivity differences, SZAs) that affect the retrieval of LST. In the RMSE differences, the size of the circles inside the grids represents the improvement rate. In the figure, the white part indicates that there are no data that correspond to the condition (Table 2). As noted by Cho and Suh [25], one of the most distinctive features of CSW_v1.0 is that the RMSE significantly increases with the increase in the lapse rate or BTD value. In addition, the error becomes larger in proportion to the size of the surface emissivity difference and SZA value. In CSW_2.0, the RMSE decreased in most of the conditions, thus demonstrating the enhanced LST retrieval performance. Specifically, as a result of considering the lapse rate and BTD in the algorithm development process, it was found that a high improvement rate could be demonstrated when the lapse rate lies between $+6 \mathrm{~K}$ and $+16 \mathrm{~K}$ and the BTD is between $+4 \mathrm{~K}$ and $+7 \mathrm{~K}$, regardless of the surface emissivity and SZA. However, errors increased in CSW_v2.0 under certain conditions, e.g., when the SZA is less than $10^{\circ}$ and the lapse rate lies between $+2 \mathrm{~K}$ and $+8 \mathrm{~K}$ (Case 1 ) and when the surface emissivity difference is greater than or equal to 0.008 and the BTD is $-3 \mathrm{~K}$, i.e., under very dry conditions (Case 2). Case 1 may be explained by the small number of TIGR points that fell within the range of SZA $\leq 10^{\circ}$ (Table 2). In Case 2, it seems that the contradicting effect between the atmospheric aerosols and large BTD values caused by large surface emissivity differences between 
the two infrared channels was not properly reflected in the dry algorithm. This aspect will have to be explored later in an in-depth analysis.

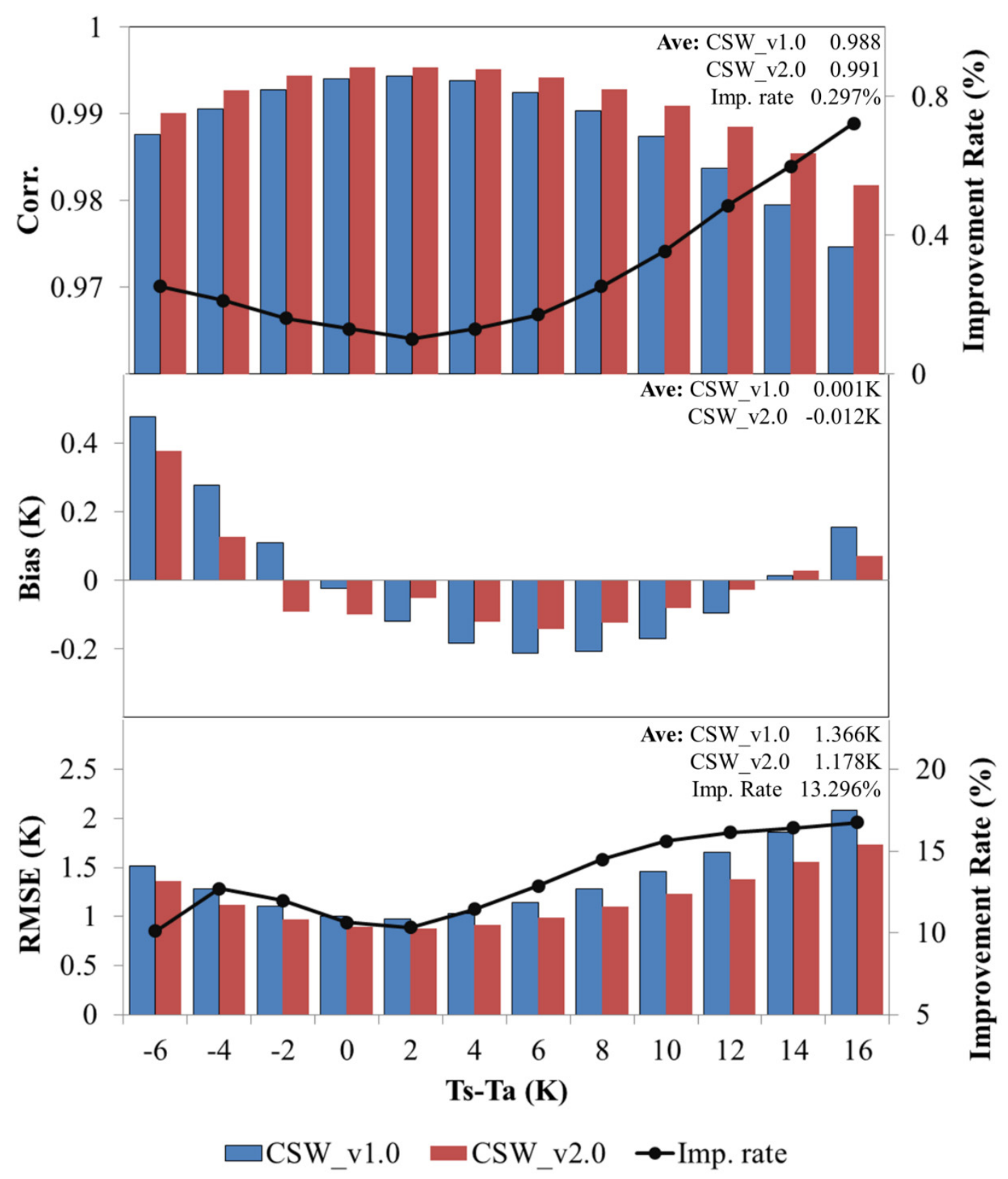

Figure 4. Estimation skills (bar graph) and improvement rate (line) of COMS split-window LST retrieval algorithms, Version 1 and Version 2, according to the temperature differences between LST and air temperature.

\subsection{Validation of CSW_v2.0 Using MODIS LST Data}

To evaluate the LST retrieval performance of CSW_v2.0, LSTs were retrieved using the COMS data collected on the 15th and 30th days of each month for one year from April 2011 to March 2012. Since LST can be retrieved only when the sky is clear, retrieval was performed only on the pixels of clear sky from the cloud mask dataset from COMS for the northern hemisphere, which was obtained from the NMSC of 
KMA. Furthermore, for the surface emissivity data that are needed when using the split-window method, values identical to those of Cho and Suh [25] were used to evaluate the algorithm improvement effects.

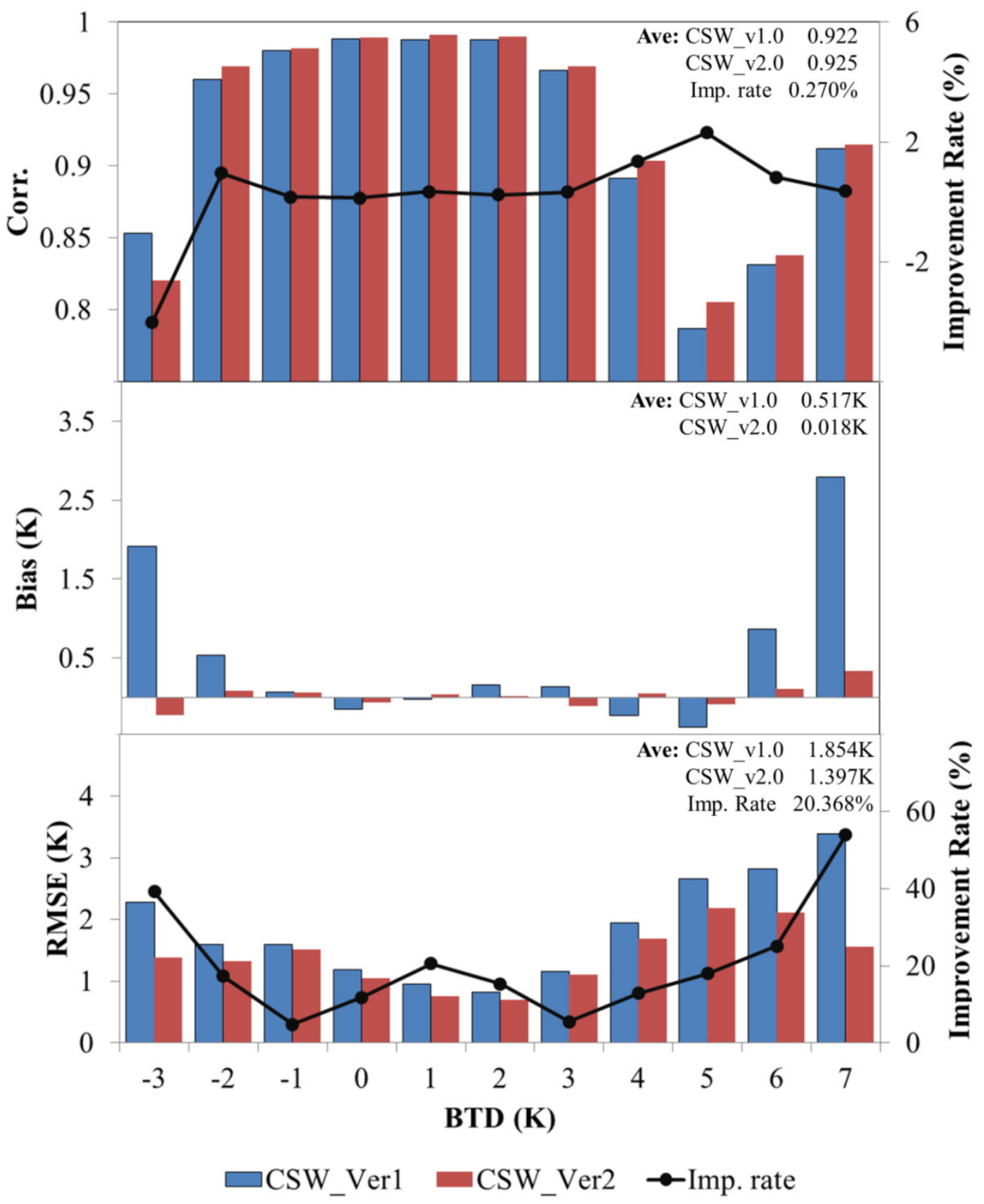

Figure 5. Same as Figure 4 except the data shows the brightness temperature difference.

As is well known, there are only a limited number of ground observation data points that can evaluate the accuracy of LSTs derived from satellites [11]. In this study, MODIS (MOD11_L2, MYD11_L2, Version 5) LST was used as an alternative method for the comparative evaluation because it is known for its relatively high retrieval accuracy, as shown in the studies of Cho and Suh [25] and Frey et al. [38]. Since LST is subjected to large spatiotemporal variations, the spatiotemporal resolutions of the two datasets were matched under strict conditions to ensure an unbiased comparison, as in other studies such as that by Cho and Suh [25]. First, we selected the MODIS pixel, for which the distance from the center of each pixel was closest, while the observation time difference between two satellite data points was less 
than $\pm 5 \mathrm{~min}$. Since the spatial resolution of COMS IR1 and IR2 was $4 \mathrm{~km}$ whereas that of MODIS LST was $1 \mathrm{~km}$, the comparison was performed via simple mean comparisons only when all the surrounding 25 $(5 \times 5)$ pixels for the selected MODIS pixel were land and when the sky was clear.
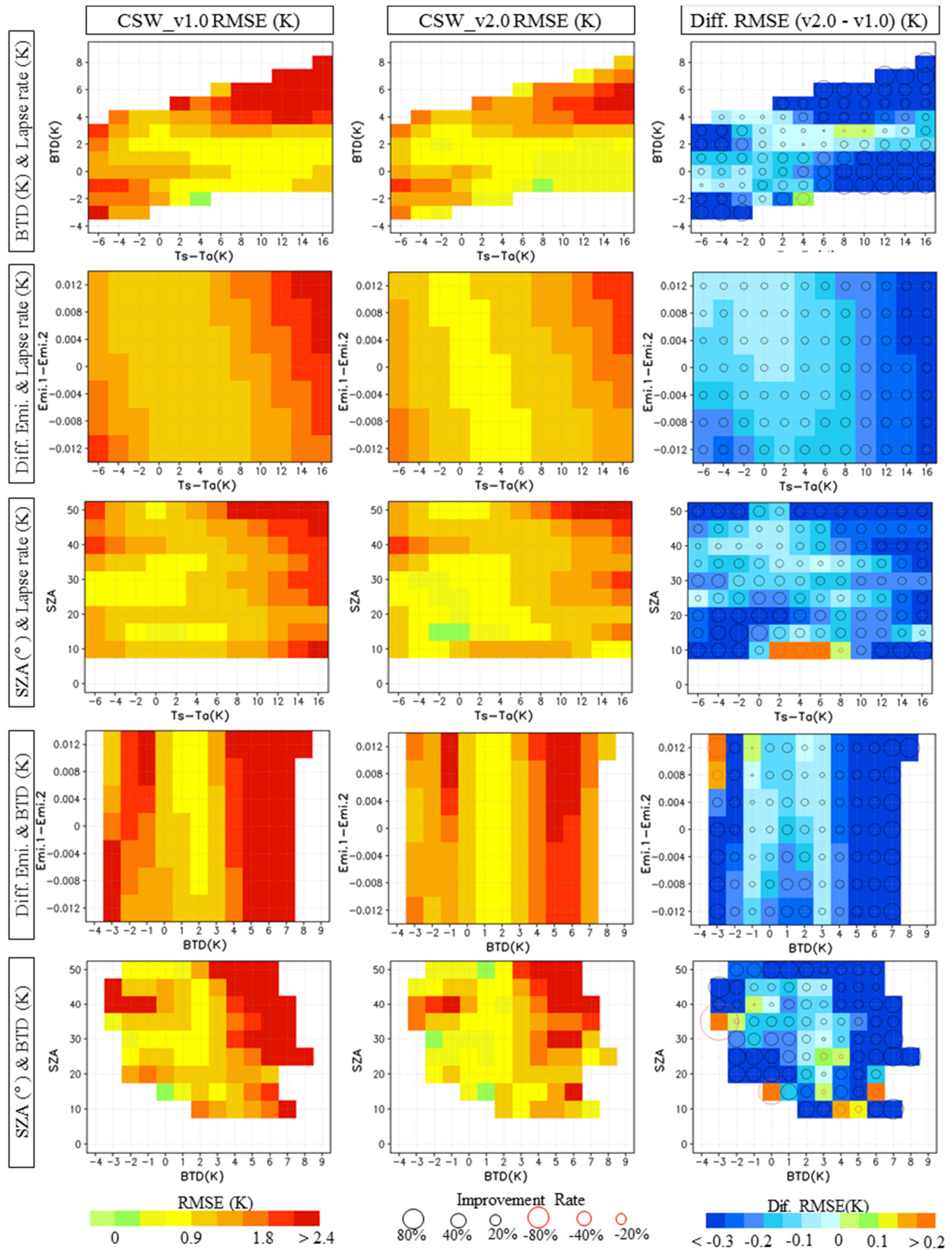

Figure 6. Distributions of RMSEs for two COMS split-window LST algorithms, Version 1 (left) and Version 2 (middle), and their differences (right) according to the different impacting factors. 


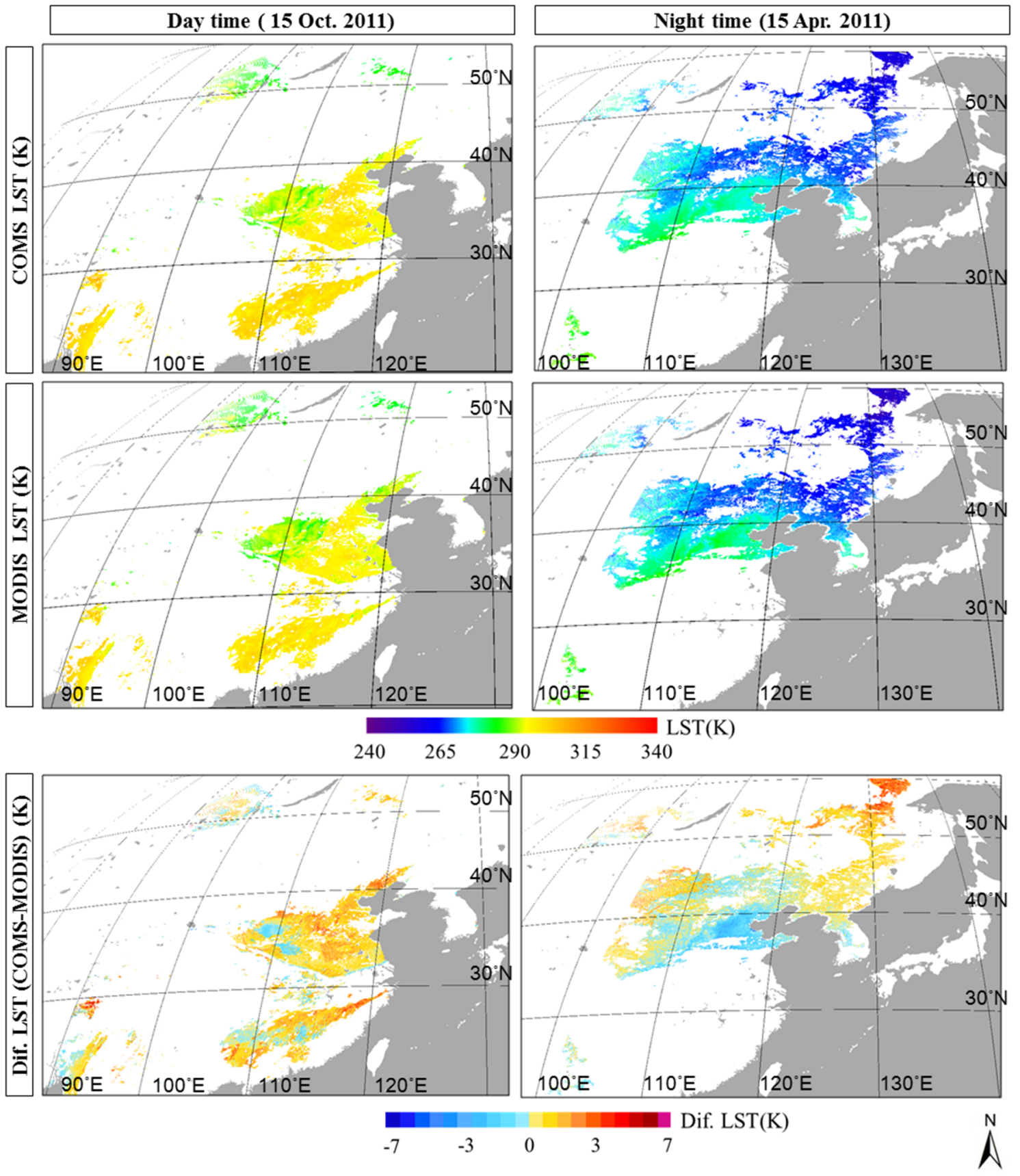

Figure 7. Spatial distribution of COMS LST and MODIS LST data and their differences for the two selected days during autumn and spring.

Figures 7-9 show the LSTs retrieved from CSW_v2.0 and MODIS LST and the spatial distribution of their differences according to season and day/night. Only the pixels that satisfy the aforementioned spatiotemporal matching conditions were compared, and the data collected at an interval of 15 min were compiled and expressed in one chart per day. Therefore, discontinuities can be observed along the path of MODIS on the spatial distribution. As shown in the figures, the spatial distributions of COMS LST and MOIDS LST were similar regardless of the season and day/night, and the differences for the two temperatures were distributed within a range of $\pm 5 \mathrm{~K}$. Furthermore, CSW_v2.0 does not seem to contain systematic errors since the temperature differences for the two datasets are diversely distributed depending on the season, day/night, and geographic location. Consequently, most of the negative deviations of CSW_v1.0 at night, mentioned by Cho and Suh [25], were resolved. 
Figure 10 shows the scatter plots between the MODIS LST and the LST retrieved by CSW_v2.0 for different seasons. The LSTs retrieved by CSW_v2.0 generally matched well with the MODIS LSTs regardless of the season and LST values. However, a remarkable warm bias was exhibited below $260 \mathrm{~K}$ in April and December and above $300 \mathrm{~K}$ in August. Furthermore, regardless of the month, differences of $5 \mathrm{~K}$ or higher were observed between the two temperature datasets. These differences seem to be mainly due to the SZA differences, observation time differences, and cloud sensing limitations between the two datasets, as mentioned by Cho and Suh [25].

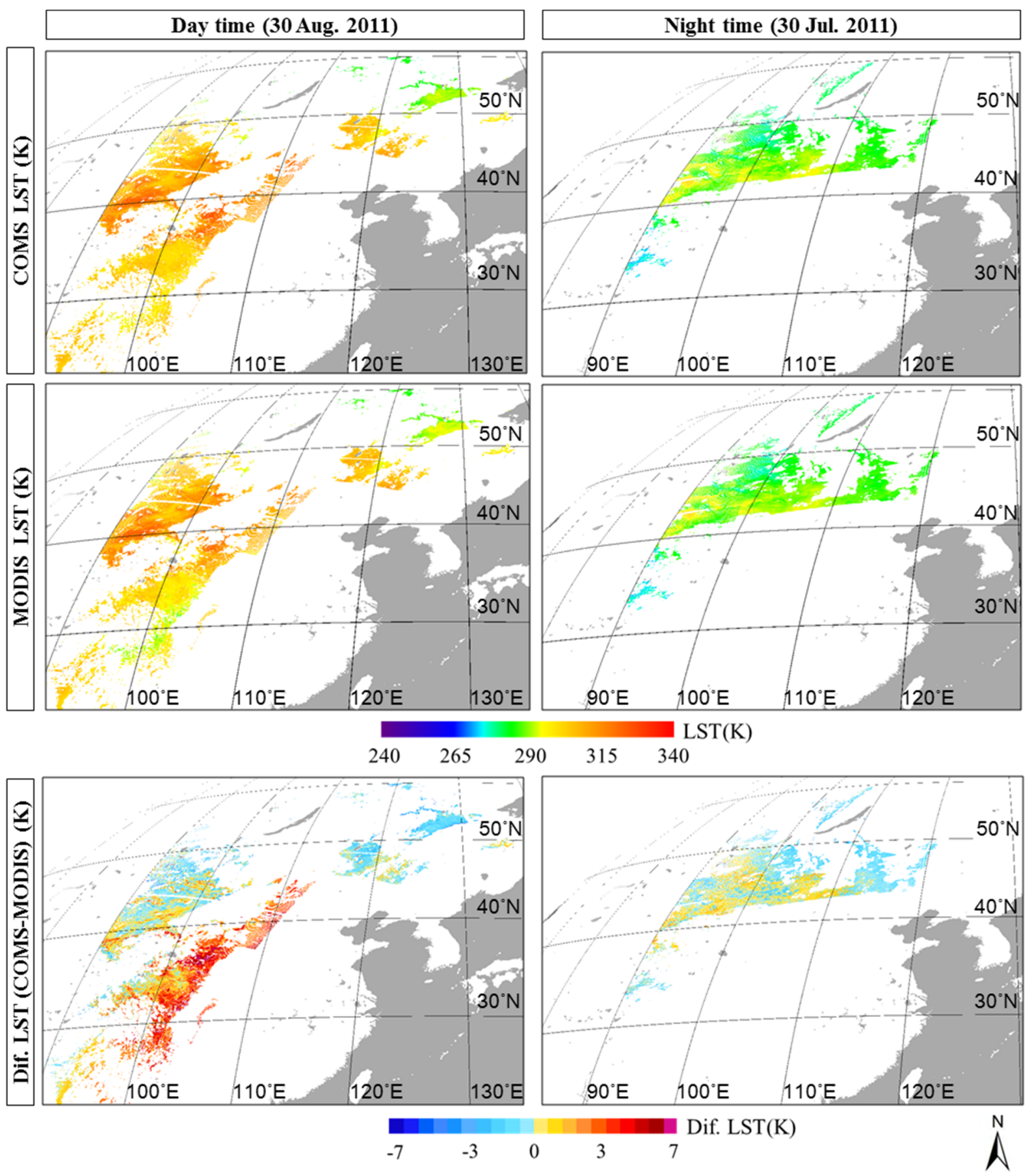

Figure 8. Spatial distribution of COMS LST and MODIS LST data and their differences for the two selected days during the summer. 

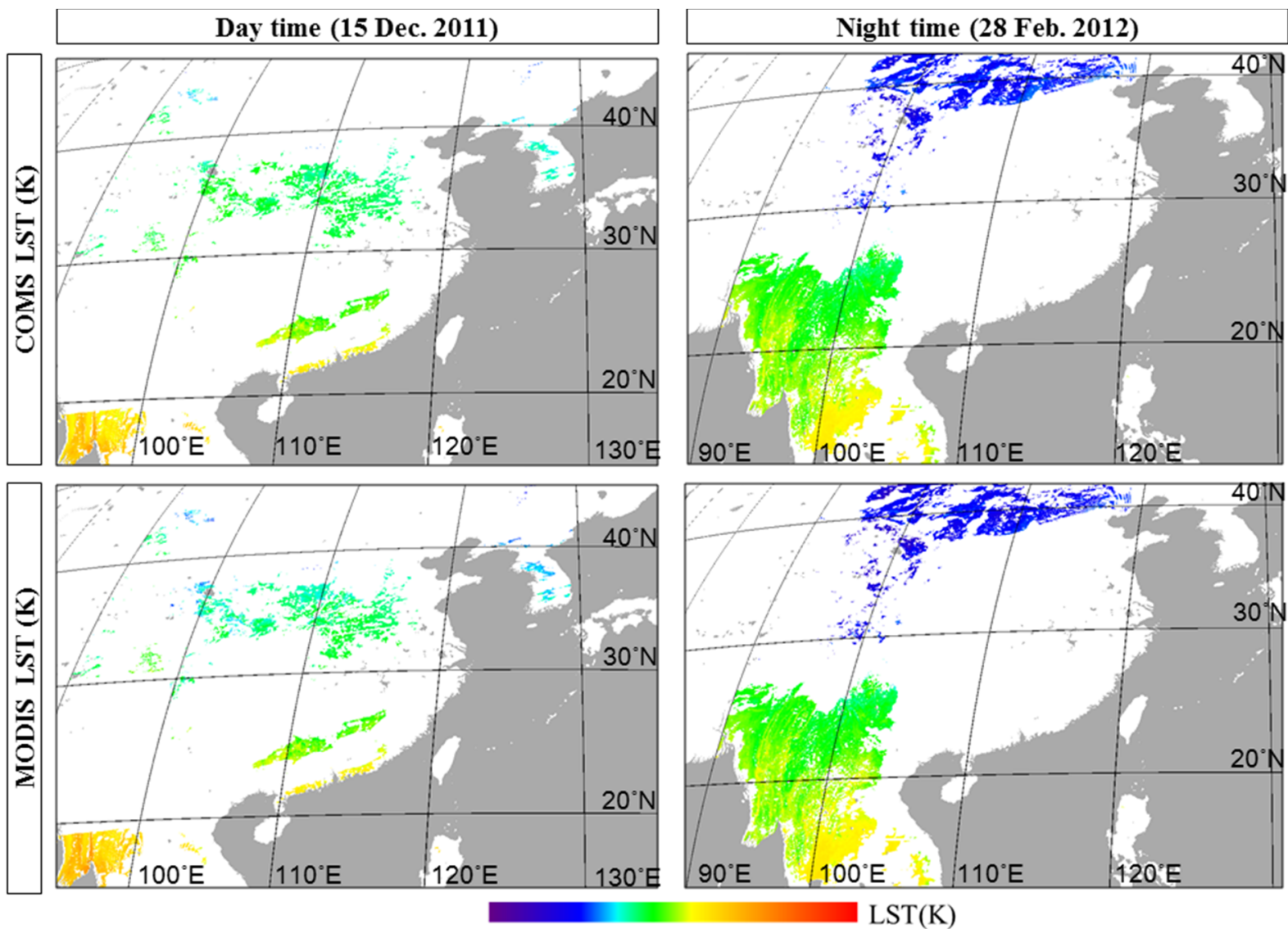

$240 \quad 265 \quad 290 \quad 315 \quad 340$

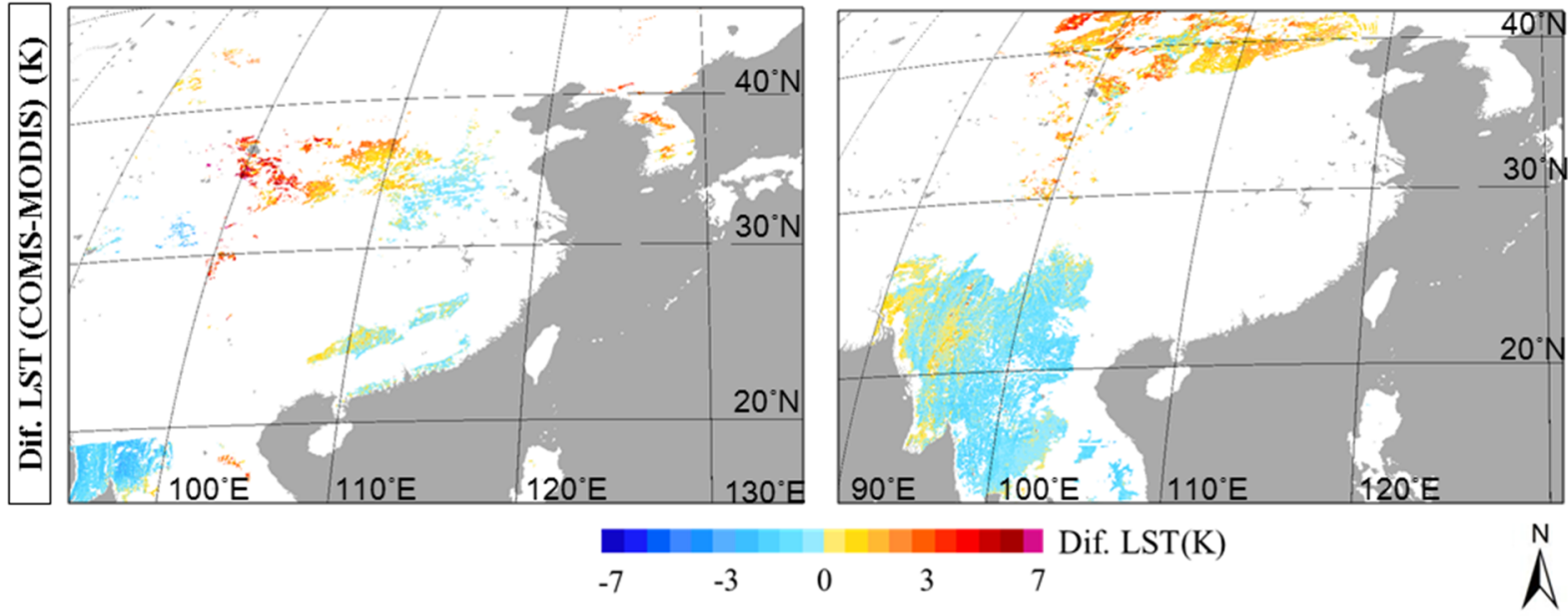

Figure 9. Same as Figure 7 except during the winter.

Table 3 shows the comparison of the results for the validation of the LSTs retrieved by CSW_v1.0 and CSW_v2.0 with MODIS LST according to the total time. The correlation coefficient was slightly improved for the day mode in most months, but in contrast, it was reduced in the night mode in all months. In relation to bias and the RMSE, the retrieval performance was improved for the night mode in most of the months, but it was reduced for the day mode in some autumn and winter months. In general, compared to CSW_v1.0, CSW_v2.0 showed improvements in regards to the correlation (from 0.988 to 0.989 ), bias (from $-1.009 \mathrm{~K}$ to $0.162 \mathrm{~K}$ ), and RMSE (from $2.613 \mathrm{~K}$ to $2.237 \mathrm{~K}$ ), and it was successful at retrieving LSTs at a similar level to MODIS. 
(a) Spring / Autumn

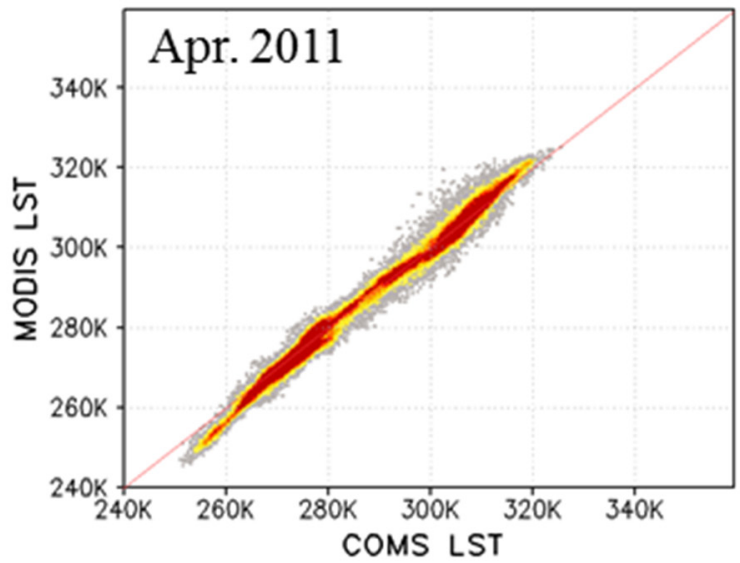

(b) Summer

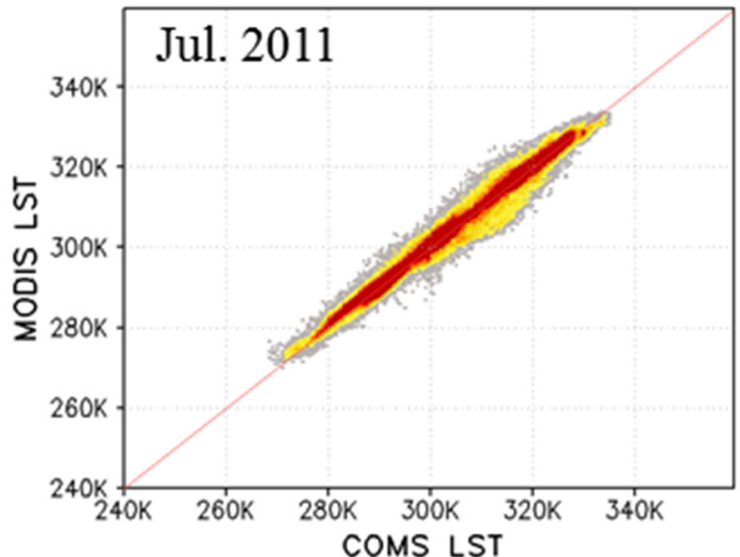

(c) Winter

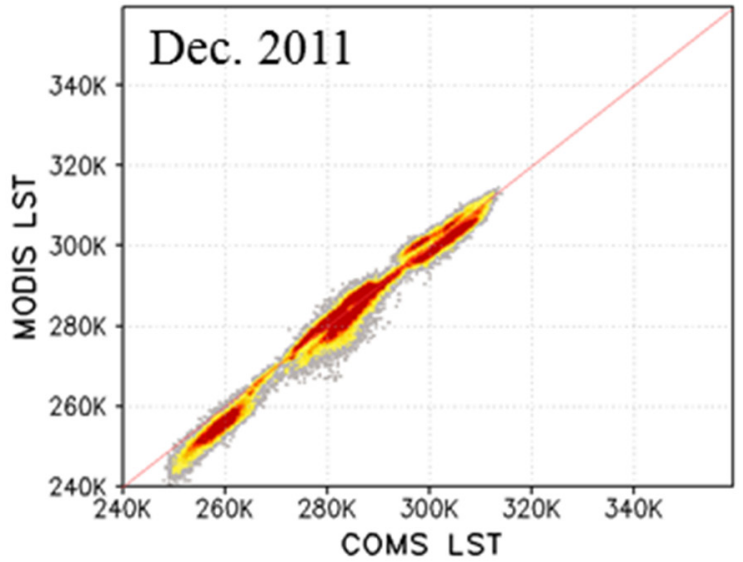

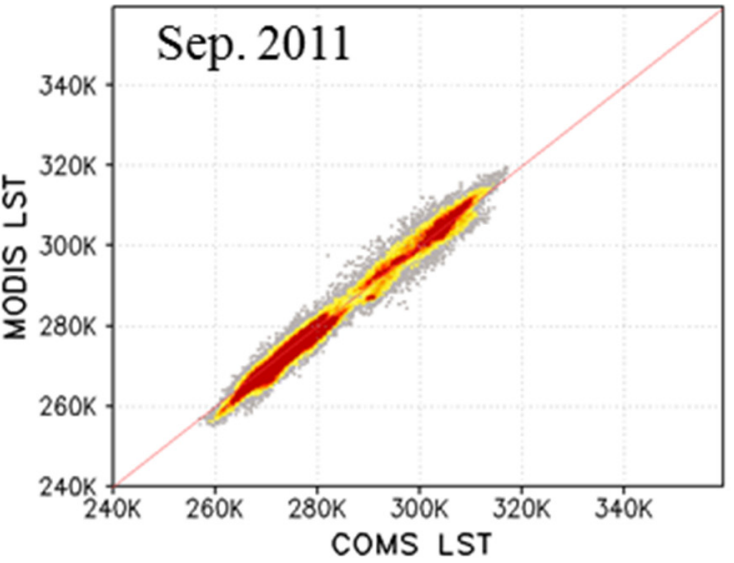
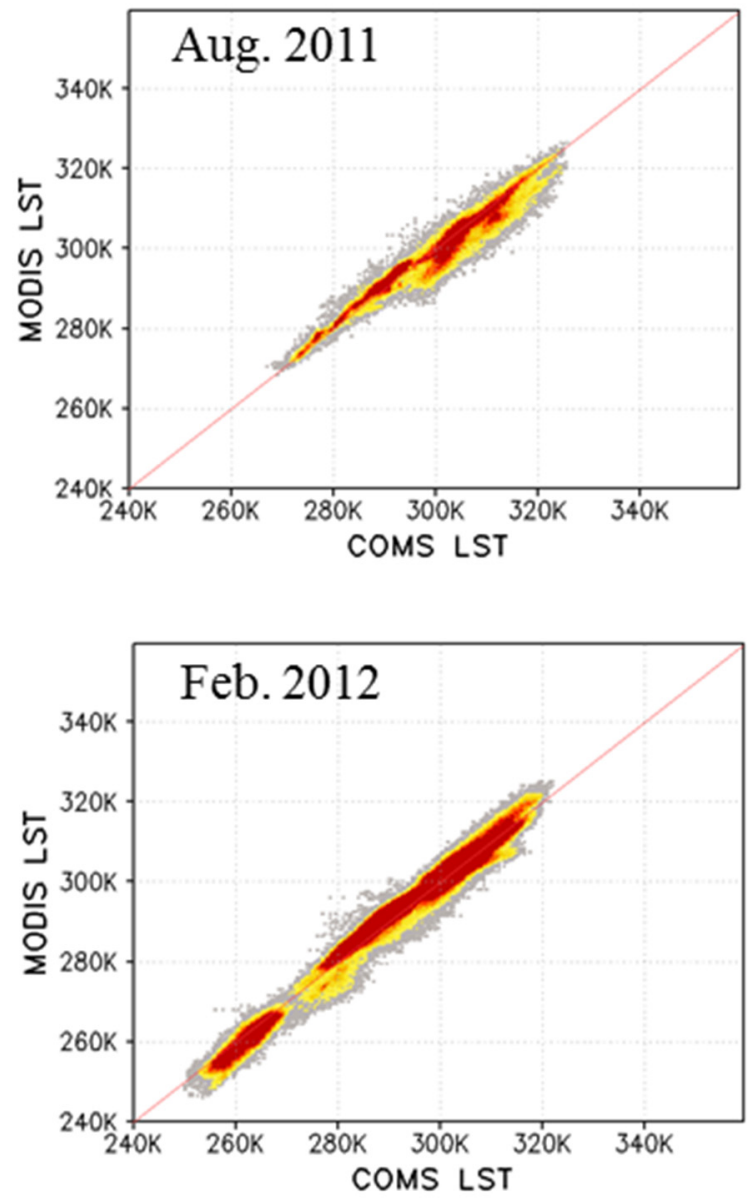

Figure 10. Scatter plot of COMS LST versus MODIS LST for the selected months. (a) Spring/Autumn, (b) Summer, (c) Winter. 
Table 3. Comparison result between the LST data derived by CSW_v1.0 (CSW_v2.0) and MODIS LST data of 2011. Bold characters and red colors indicate the cases improved and deteriorated with CSW_v2.0, respectively.

\begin{tabular}{c|c|ccccccccccccc}
\hline \multicolumn{2}{c|}{ Mon. } & $\mathbf{4}$ & $\mathbf{5}$ & $\mathbf{6}$ & $\mathbf{7}$ & $\mathbf{8}$ & $\mathbf{9}$ & $\mathbf{1 0}$ & $\mathbf{1 1}$ & $\mathbf{1 2}$ & $\mathbf{1}$ & $\mathbf{2}$ & $\mathbf{3}$ & Ave. \\
\hline \multirow{2}{*}{ Corr. } & Ver1 & 0.995 & 0.995 & 0.984 & 0.986 & 0.968 & 0.993 & 0.991 & 0.991 & 0.987 & 0.982 & 0.990 & $\mathbf{0 . 9 9 2}$ & 0.988 \\
& Ver2 & 0.995 & $\mathbf{0 . 9 9 6}$ & $\mathbf{0 . 9 8 6}$ & $\mathbf{0 . 9 9 0}$ & 0.968 & 0.993 & $\mathbf{0 . 9 9 2}$ & $\mathbf{0 . 9 9 4}$ & $\mathbf{0 . 9 9 1}$ & $\mathbf{0 . 9 8 3}$ & 0.990 & 0.991 & $\mathbf{0 . 9 8 9}$ \\
\hline \multirow{2}{*}{ Bias } & Ver1 & -1.506 & -2.421 & -1.415 & -1.220 & $-\mathbf{0 . 0 1 0}$ & -1.289 & $\mathbf{0 . 0 7 9}$ & $-\mathbf{0 . 1 6 6}$ & $-\mathbf{0 . 0 0 4}$ & -1.386 & -1.080 & -1.692 & -1.009 \\
$($ K) & Ver2 & $\mathbf{0 . 2 2 4}$ & $-\mathbf{0 . 5 2 8}$ & $\mathbf{0 . 7 4 3}$ & $-\mathbf{0 . 2 2 1}$ & 0.717 & $\mathbf{0 . 6 2 3}$ & 1.360 & 1.089 & 1.093 & $-\mathbf{0 . 3 9 3}$ & $\mathbf{- 0 . 2 7 8}$ & $-\mathbf{0 . 9 2 7}$ & $\mathbf{0 . 2 9 2}$ \\
\hline RMSE & Ver1 & 2.477 & 3.056 & 2.737 & 2.735 & 3.175 & 2.075 & $\mathbf{1 . 9 8 8}$ & 2.136 & 2.662 & 3.126 & 2.506 & 2.681 & 2.613 \\
$($ K) & Ver2 & $\mathbf{1 . 8 5 4}$ & $\mathbf{1 . 8 6 3}$ & $\mathbf{2 . 0 1 6}$ & $\mathbf{2 . 0 3 3}$ & $\mathbf{2 . 8 8 3}$ & $\mathbf{1 . 8 3 1}$ & 2.134 & $\mathbf{2 . 1 2 3}$ & $\mathbf{2 . 5 7 3}$ & $\mathbf{2 . 7 2 4}$ & $\mathbf{2 . 3 2 3}$ & $\mathbf{2 . 4 9 0}$ & $\mathbf{2 . 2 3 7}$ \\
\hline
\end{tabular}

\section{Summary}

In this study, to resolve the problems of CSW_v1.0 [25], which retrieves LST from the COMS IR1 and IR2 data, we developed six types of LST retrieval equations (CSW_v2.0) based on the sizes of lapse rate and water vapor/aerosol effects.

For CSW_v1.0, large errors were detected in the cases where superadiabatic lapse rates and inversion layers were present and under the conditions of large water vapor and aerosol effects. To solve this problem, (1) RTM simulations were performed by dividing the lapse rate condition into day and night and (2) six types of LST retrieval equations were developed by classifying the cases as dry, normal, and wet depending on the BTD values that consider the effects of water vapor and aerosols. For the pixels corresponding to the boundaries between algorithms, a weighted combination algorithm was developed and applied to resolve the discontinuities between day/night and LST equations.

Compared to CSW_v1.0, the upgraded version CSW_2.0 developed in this study maintained high levels of correlation between the prescribed LSTs and retrieved LSTs (0.99), had a low bias ( $-0.01 \mathrm{~K})$, and the RMSE improved from $1.41 \mathrm{~K}$ to $1.21 \mathrm{~K}$. Particularly, CSW_v2.0 improved the systematic problems of CSW_v1.0 that were encountered when inversion layers and superadiabatic lapse rates were present and under conditions of large BTD values and surface emissivity differences, and it reduced the bias and RMSE by $10-50 \%$. Furthermore, the LSTs were retrieved by applying CSW_v2.0 to the COMS data collected on the 15th and 30th day in every month; and as a result of comparing these data with the MODIS LSTs, it was confirmed that the LSTs were retrieved within $\pm 5 \mathrm{~K}$ regardless of the season, day/night, and location. Particularly, CSW_v2.0 resolved many of the problems of CSW_v1.0 that involved systematic underestimations of the LST at night. Compared to the COMS LST retrieved with CSW_v1.0, those retrieved with CSW_v2.0 showed improvements in the monthly average correlation from 0.988 to 0.989 , bias from $-1.009 \mathrm{~K}$ to $0.292 \mathrm{~K}$, and RMSE from $2.613 \mathrm{~K}$ to $2.237 \mathrm{~K}$; thus, errors were reduced considerably.

As LST over East Asia can be retrieved over short cycles and with high accuracy using the CSW_v2.0 developed in this study, it is expected that the proposed method will contribute to accuracy improvements in various studies such as those involving urban heat island assessments, air temperature estimates, and validations of numerical weather prediction models or climate models. However, retrieving the LSTs at dawn and twilight by the weighted combination of day and night LSTs posed a problem, i.e., CSW_v2.0 showed decreased retrieval performance compared to CSW_v1.0. Likewise, 
some conditions (e.g., at night during the autumn and winter) resulted in a lowered retrieval performance compared to CSW_v1.0. Therefore, it will be necessary to develop a more elaborate LST retrieval algorithm to retrieve the LST within $\pm 2 \mathrm{~K}$ in future studies; such a level is required in various LST data application fields such as validation of numerical simulations, agriculture, urban heat-island assessments, and evapotranspiration estimations.

\section{Acknowledgments}

We are thankful to the National Meteorological Satellite Center (NMSC) of the Korea Meteorological Administration (KMA) for providing the 1-year COMS Level-1B and cloud mask data. We also deeply appreciate the National Aeronautics and Space Administration for providing the 1-year MODIS LST data. This work was funded by the KMA Research and Development program under Grant Center for Atmospheric and Earthquake Research (CATER) 2012-2067.

\section{Author Contributions}

All authors contributed extensively to the work presented in this paper. Myoung-Seok Suh proposed the research idea. A-Ra Cho and Youn-Young Choi designed the algorithms and analyzed the data. All authors interpreted the results and wrote the paper.

\section{Conflicts of Interest}

The authors declare no conflicts of interest.

\section{References}

1. Noilhan, J.; Planton, S. A simple parameterization of land surface processes for meteorological models. Mon. Weather Rev. 1989, 117, 536-549.

2. Aires, F.; Prigent, C.; Rossow, W.; Rothstein, M. A new neural network approach including first guess for retrieval of atmospheric water vapor, cloud liquid water path, surface temperature, and emissivities over land from satellite microwave observations. J. Geophys. Res. 2001, 106, 14887-14907.

3. Sun, D.; Pinker, R.T. Estimation of land surface temperature from a Geostationary Operational Environmental Satellite (GOES-8). J. Geophys. Res. 2003, 108, doi:10.1029/2002JD002422.

4. Pinheiro, A.; Mahoney, R.; Privette, J.; Tucker, C. Development of a daily long term record of NOAA-14 AVHRR land surface temperature over Africa. Remote Sens. Environ. 2006, 103, 153-164.

5. Hachem, S.; Allard, M.; Duguay, C. Using the MODIS land surface temperature product for mapping permafrost: An application to northern Québec and Labrador, Canada. Permafr. Periglac. Process. 2009, 20, 407-416.

6. Benali, A.; Carvalho, A.; Nunes, J.; Carvalhais, N.; Santos, A. Estimating air surface temperature in Portugal using MODIS LST data. Remote Sens. Environ. 2012, 124, 108-121.

7. Guo, M.; Wang, X.; Li, J.; Yi, K.; Zhong, G.; Tani, H. Assessment of global carbon dioxide concentration using MODIS and GOSAT data. Sensors 2012, 12, 16368-16389. 
8. Pal, S.; Xueref-Remy, I.; Ammoura, L.; Chazette, P.; Gibert, F.; Royer, P.; Dieudonne, E.; Dupont, J.C.; Haeffelin, M.; Lac, C.; et al. Spatio-temporal variability of the atmospheric boundary layer depth over the Paris agglomeration: An assessment of the impact of the urban heat island intensity. Atmos. Environ. 2012, 63, 261-275.

9. Lac, C.; Donnelly, R.P.; Masson, V.; Pal, S.; Donier, S.; Queguiner, S.; Tanguy, G.; Ammoura, L.; Xueref-Remy, I. $\mathrm{CO}_{2}$ dispersion modelling over Paris region within the $\mathrm{CO}_{2}$-MEGAPARIS project. Atmos. Chem. Phys. 2013, 13, 4941-4961.

10. Kustas, W.; Norman, J. Use of remote sensing for evapotranspiration monitoring over land surfaces. Hydrolog. Sci. J. 1996, 41, 495-516.

11. Moran, M.S.; Jackson, R.D. Assessing the spatial distribution of evapotranspiration using remotely sensed inputs. J. Environ. Qual. 1991, 20, 725-737.

12. Wan, Z.; Dozier, J. A generalized split-window algorithm for retrieving land-surface temperature from space. IEEE Trans. Geosci. Remote Sens. 1996, 34, 892-905.

13. Li, Z.-L.; Tang, B.-H.; Wu, H.; Ren, H.; Yan, G.; Wan, Z.; Trigo, I.F.; Sobrino, J.A. Satellite-derived land surface temperature: Current status and perspectives. Remote Sens. Environ. 2013, 131, 14-37.

14. Prata, A.; Caselles, V.; Coll, C.; Sobrino, J.; Ottle, C. Thermal remote sensing of land surface temperature from satellites: Current status and future prospects. Remote Sens. Rev. 1995, 12, 175-224.

15. Cristòbal, J.; Jimènez-Muñez, J.C.; Sobrino, J.A; Ninyerola, M.; Pons, X. Improvements in land surface temperature retrieval from the Landsat series thermal band using water vapor and air temperature. J. Geophys. Res. 2009, 114, doi:10.1029/2008JD010616.

16. Price, J.C. Land surface temperature measurements from the split window channels of the NOAA 7 Advanced Very High Resolution Radiometer. J. Geophys. Res. 1984, 89, 7231-7237.

17. Kerr, Y.H.; Lagouarde, J.P.; Imbernon, J. Accurate land surface temperature retrieval from AVHRR data with use of an improved split window algorithm. Remote Sens. Environ. 1992, 41, 197-209.

18. Ulivieri, C.; Castronuovo, M.; Francioni, R.; Cardillo, A. A split window algorithm for estimating land surface temperature from satellites. Adv. Space Res. 1994, 14, 59-65.

19. Han, K.-S.; Viau, A.; Anctil, F. An analysis of GOES and NOAA derived land surface temperatures estimated over a boreal forest. Int. J. Remote Sens. 2004, 25, 4761-4780.

20. Suh, M.-S.; Kim, S.-H.; Kang, J.-H. A comparative study of algorithms for estimating land surface temperature from MODIS data. Kor. J. Remote Sens. 2008, 24, 65-78.

21. Prata, A.; Cechet, R. An assessment of the accuracy of land surface temperature determination from the GMS-5 VISSR. Remote Sens. Environ. 1999, 67, 1-14.

22. Peres, L.F.; DaCamara, C.C. Land surface temperature and emissivity estimation based on the two-temperature method: Sensitivity analysis using simulated MSG/SEVIRI data. Remote Sens. Environ. 2004, 91, 377-389.

23. Inamdar, A.K.; French, A. Disaggregation of GOES land surface temperatures using surface emissivity. Geophys. Res. Lett. 2009, 36, doi:10.1029/2008GL036544.

24. Pinker, R.T.; Sun, D.; Hung, M.-P.; Li, C.; Basara, J.B. Evaluation of satellite estimates of land surface temperature from GOES over the United States. J. Appl. Meteorol. Climatol. 2009, 48, 167-180.

25. Cho, A.-R.; Suh, M.-S. Evaluation of land surface temperature operationally retrieved from Korean geostationary satellite (COMS) data. Remote Sens. 2013, 5, 3951-3970. 
26. Sobrino, J.; Romaguera, M. Land surface temperature retrieval from MSG1-SEVIRI data. Remote Sens. Environ. 2004, 92, 247-254.

27. Kalma, J.D.; McVicar, T.R.; McCabe, M.F. Estimating land surface evaporation: A review of methods using remotely sensed surface temperature data. Surv. Geophys. 2008, 29, 421-469.

28. Dousset, B.; Gourmelon, F.; Laaidi, K.; Zeghnoun, A.; Giraudet, E.; Bretin, P.; Mauri, E. Vandentorren, S. Satellite monitoring of summer heat waves in the Paris metropolitan area. Int. J. Climatol. 2011, 31, 313-323.

29. Peng, S.; Piao, S.; Ciais, P.; Friedlingstein, P.; Ottle, C.; Bréon, F.M.; Nan, H.; Zhou, L.; Myneni, R.B. Surface urban heat island across 419 global big cities. Environ. Sci. Technol. 2011, 46, 696-703.

30. Roth, M. Effect of cities on local climates. In Proceedings of the 2002 Workshop of IGES/APN Mega-City Project, Kitakyushu, Japan, 23-25 January 2002; pp. 1-13.

31. Choi, Y.-Y.; Suh, M.-S.; Park, K.-H. Assessment of surface urban heat islands over three megacities in East Asia using land surface temperature data retrieved from COMS. Remote Sens. 2014, 6, 5852-5867.

32. Kerr, Y.H.; Lagouarde, J.P.; Nerry, F.; Ottlé, C. Land surface temperature retrieval techniques and applications. In Thermal Remote Sensing in Land Surface Processes; CRC Press: Boston, MA, USA, 2004; pp. 33-109.

33. Dash, P. Land Surface Temperature and Emissivity Retrieval from Satellite Measurements. Available online: http://d-nb.info/97521960x/34/ (accessed on 9 October 2014).

34. Behrendt, A.; Pal, S.; Aoshima, F.; Bender, M.; Blyth, A; Corsmeier, U.; Cuesta, J.; Dick, G.; di Girolamo, P; Dominger, M.; et al. Observation of convection initiation processes with a suite of state-of-the-art research instruments during COPS IOP8b. Q. J. R. Meteorol. Soc. 2011, 137, 81-100.

35. Goïta, K.; Royer, A.; Bussières, N. Crseharacterization of land surface thermal structure from NOAA-AVHRR data over a northern ecosystem. Remote Sens. Environ. 1997, 60, 282-298.

36. Sobrino, J.; Raissouni, N. Toward remote sensing methods for land cover dynamic monitoring: Application to Morocco. Int. J. Remote Sens. 2000, 21, 353-366.

37. Sobrino, J.; Sòria, G.; Prata, A. Surface temperature retrieval from Along Track Scanning Radiometer 2 data: Algorithms and validation. J. Geophys. Res.: Atmos. 2004, 109, D1 1101.

38. Sòria, G.; Sobrino, J.A. ENVISAT/AATSR derived land surface temperature over a heterogeneous region. Remote Sens. Environ. 2007, 111, 409-422.

39. National Meteorological Satellite Center (NMSC). Available online: http://nmsc.kma.go.kr (accessed on 9 October 2014).

40. Valor, E.; Caselles, V. Mapping land surface emissivity from NDVI: Application to European, African, and South American areas. Remote Sens. Environ. 1996, 57, 167-184.

41. Thermodynamic Initial Guess Retrieval (TIGR). Available online: http://ara.abct.lmd.polytechnique.fr/ index.php?page=tigr (accessed on 9 October 2014).

42. Wan, Z. New refinements and validation of the MODIS land-surface temperature/emissivity products. Remote Sens. Environ. 2008, 112, 59-74.

43. Frey, C.M.; Kuenzer, C.; Dech, S. Quantitative comparison of the operational NOAA-AVHRR LST product of DLR and the MODIS LST product V005. Int. J. Remote Sens. 2012, 33, 7165-7183. 
44. Berk, A.; Anderson, G.P.; Acharya, P.K.; Chetwynd, J.H.; Bernstein, L.S.; Shettle, E.P.; Matthew, M.W.; Adler-Golden, S.M. MODTRAN4 Users's Mannual; Air Force Research Laboratory: Hanscom AFB, MA, USA, 1999.

(C) 2015 by the authors; licensee MDPI, Basel, Switzerland. This article is an open access article distributed under the terms and conditions of the Creative Commons Attribution license (http://creativecommons.org/licenses/by/4.0/). 